\title{
Using Recycled Aggregates from Construction and Demolition Waste in Unbound Layers of Pavements
}

\author{
Sajjad Pourkhorshidi ${ }^{1,2, *}$, Cesare Sangiorgi ${ }^{1}\left(\mathbb{D}\right.$, Daniele Torreggiani ${ }^{2}$ and Patrizia Tassinari ${ }^{2}$ \\ 1 Department of Civil, Chemical, Environmental and Materials Engineering (DICAM), University of Bologna, \\ Via Terracini 28, 40131 Bologna, Italy; cesare.sangiorgi4@unibo.it \\ 2 Department of Agricultural and Food Sciences (DISTAL), University of Bologna, Viale Fanin 48, \\ 40127 Bologna, Italy; daniele.torreggiani@unibo.it (D.T.); patrizia.tassinari@unibo.it (P.T.) \\ * Correspondence: sajjad.pourkhorshid2@unibo.it; Tel.: +39-3288155533
}

Received: 29 September 2020; Accepted: 5 November 2020; Published: 11 November 2020

\begin{abstract}
Pavements are an expensive part of transportation infrastructures, as their construction and maintenance require large amounts of resources and materials every year and all over the world. A sustainable solution for considering environmental concerns about roads and pavements, in general, is utilizing recycled materials for their construction. This has been shown to lower the carbon footprint of the construction sector and to result in natural resource conservation, in reduction of harmful emissions and in minimization of overall costs for pavement construction and maintenance. One of the main groups of recycled materials which has attracted much attention since the end of the last century is construction and demolition waste aggregates (CDW). This paper reviews the completed studies referring to the use of the construction and demolition waste aggregates in unbound layers of pavements and compare the in-hand results from various engineering assessments of these aggregates and mixes. A number of tests and evaluations are applied in order to enhance the required quality and durability of the pavements under given traffic volumes traffic loads and climate actions. Today, unbound recycled aggregates (RA) are mainly used in the lower layers, such as subgrade, capping, sub-base and base, but in rural roads they can be adopted also for bound layers, towards the surface of the structure and may be constituents of bound layers and of novel surfacing applications.
\end{abstract}

Keywords: recycled materials; construction and demolition; pavements; sustainability; waste

\section{Introduction}

As traffic capacities and trucks axle weights continue to increase with growing population and development of countries, road construction and its maintenance is becoming more and more frequent all over the world. As road construction activities become more common, the need for construction materials becomes urgent [1,2]. Aggregates undertake more than $90 \% \mathrm{wt}$ of asphalt mixtures [3] and $100 \%$ of unbound layers. Thus, the construction of road infrastructures consumes millions of tons of materials each year, in particular of aggregates (crushed or natural). supplying these amounts would have a detrimental effect on nature and the environment [4]. The old materials used for the construction sites are usually landfilled and new materials are obtained for the purpose of new constructions [1].

On the other hand, even more so today when short chains for goods are desirable, in rural and sub-urban areas, agriculture plays an increasingly crucial and multifunctional role which requires careful design, not only of rural roads but also of the outdoor open working areas of farms. The sustainability of the solutions adopted for these low traffic pavements should become a central pivot of the corporate and territorial strategies in rural areas. These pavements must respond to a variety of requirements and properties, which make them a topic under increasing study and development. 
As an example, the agritourism activities and direct on-farm sale of agricultural products bring attention to the development of low-impact solutions, which combine the obvious structural and functional requirements with the environmental and landscape protection ones. Even in the design of road infrastructures in protected areas, these aspects of environmental and landscape compatibility are of high importance. The same theme is proposed for the construction of paved areas in urban and sub-urban parks or for urban surfaces where recreational activities are foreseen.

Consistent data on the quarried sand, gravel and crushed stone for production of natural aggregates adopted for construction are only available for a limited number of developed countries and for recent years. No data about the extraction of construction minerals in whole world could be found. In various studies, different methods are explained to estimate the quantities of bulk materials employed in construction. For this purpose, data on bitumen production used to indirectly extrapolate the volume of aggregates used for asphalt pavement production, assuming a weight ratio of 1:20. It has also been estimated that the overall material extraction during this century has increased by a factor of 8 . For instance, in 2005, roughly 59 giga tons of materials were extracted and used worldwide. The largest increase during this period can be observed for construction minerals, which grew by a factor of 34 . Subjected for only $15 \%$ of total construction minerals at the beginning of the XXth century, its portion increased sharply after World War II to more than $60 \%$ at the beginning of the 70 s and reached $74 \%$ in 2005 (Figure 1). After World War II, 8\% of all construction materials were estimated for sand and gravel used for the production of asphalt. This part enlarged to $14 \%$ in 1973 and since then it keep on between 10 and $15 \%$ [5].

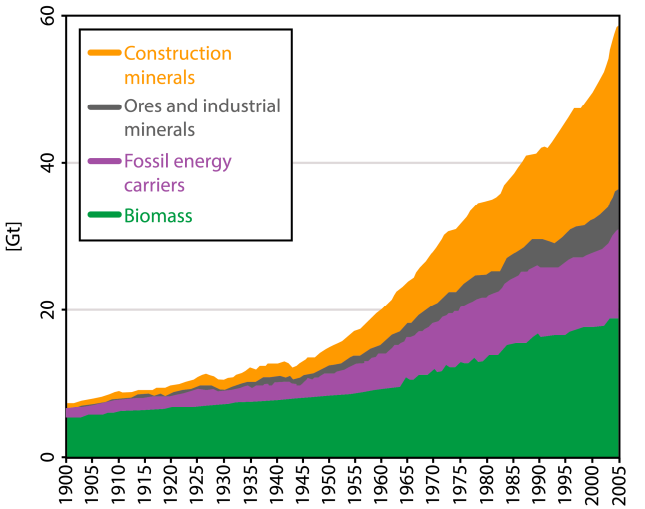

(a)

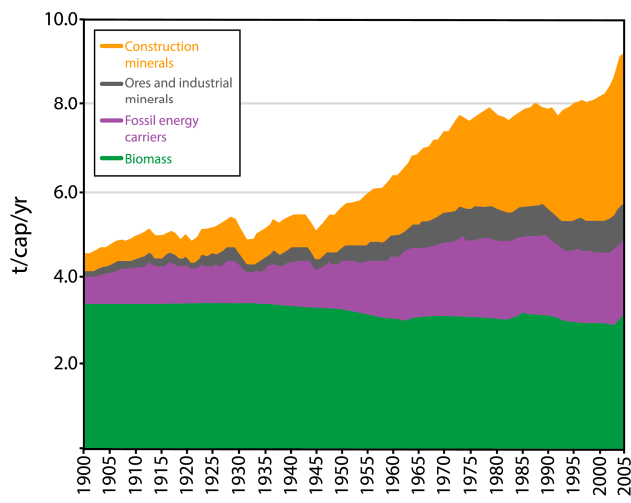

(c)

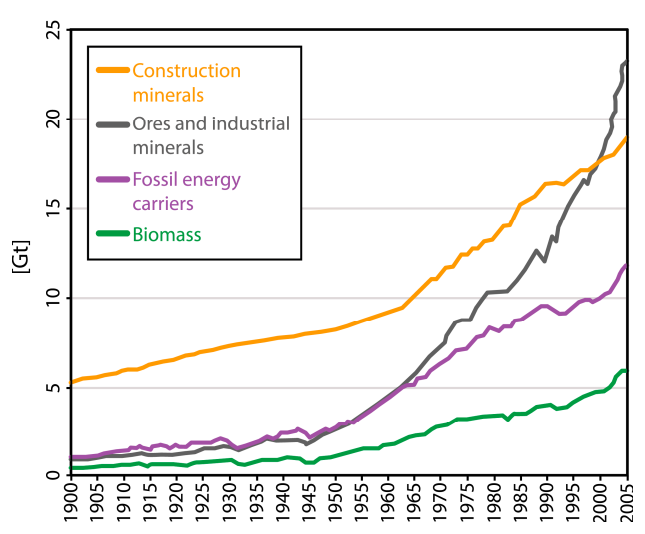

(b)

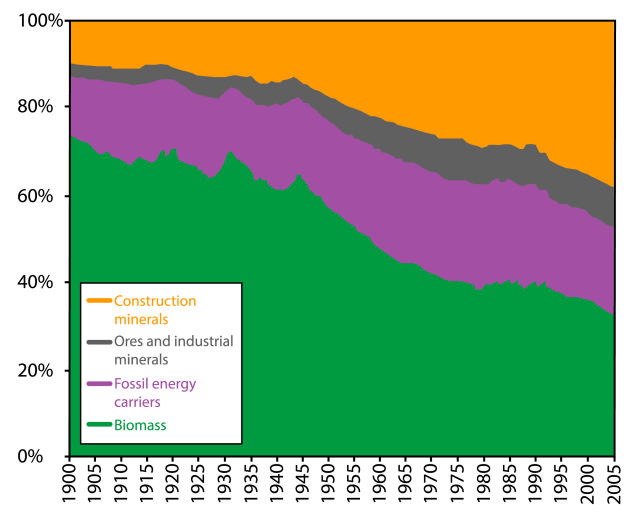

(d)

Figure 1. Materials use (on the basis of total quantity of resources extracted equals total quantity of resources used), by material types in the years 1900 to 2005. (a,b) total materials use in Giga tons (Gt) per year; (c) metabolic rate (materials use in $\mathrm{t} / \mathrm{cap} / \mathrm{year}$ ); (d) share of material types of total materials use [5]. 
In the light of the above, it is more and more important to find alternative solutions for the supply of construction materials. Besides natural aggregates, the use of recycled materials is today growing in quality and quantities, so that most of the construction projects encompass some sustainable approaches to recycling.

Construction and demolition (CD) activities generated 1.13 billion tones in China in year 2014; and over 530 million tones in United States (US). Construction activities in Europe is the largest producer of waste when compared with other industrial areas, responsible for $35 \%$ of the total waste generation which is 2 and 4 times more than the overall household waste produced respectively in US and Europe. European union overall has achieved the horizon of recovery for the year 2020, including backfilling. However, there are still eleven member countries -out of the 19- which need to improve their recovery performance for achieving the EU target [6]. The total production of construction and demolition waste in 28 countries of the European union plus Britain reached more than 368 million tons in the year 2018 [7]. Aggregates from construction and demolition waste (C\&DW or simply CDW) can indeed increasingly contribute to the global economy, while relieving utilization of natural resources and satisfying the desired material requirement in different projects. A great potential related to recycling exist, which can be activated by employing proper management approaches and introducing state-of-the-art technologies that can allow C\&D wastes to be recycled according to their quality and use [8]. Article 11.2 of the Waste Framework Directive (2008/98/EC) specifies that "Member States shall take the necessary measures designed to achieve that by 2020 a minimum of $70 \%$ (by weight) of non-hazardous construction and demolition waste excluding naturally occurring material defined in category 170504 in the List of Wastes shall be prepared for re-use, recycled or undergo other material recovery" (including backfilling operations using waste to replace other materials) [9]. Urban solid wastes contain $30-40 \%$ of waste coming from construction and demolition activities [10]. In Italy, the ratio of construction and demolition waste, which is prepared for re-use, recycled or utilized material recovery was $98 \%$ in 2018 compared to $88 \%$ of the whole European union. Mineral wastes from construction and demolition are usually concrete, bricks, and gypsum waste; insulation materials; mixed construction wastes containing glass, plastics and wood; and waste bituminous road-surfacing material [11]. According to Eurostat in 2018 Italy generated almost 41 million tons of non-hazardous waste from construction and demolition activities (Table 1), 21\% more than in 2012.

Table 1. Total major wastes generated in Italy in 2012 and 2018 [7].

\begin{tabular}{ccc}
\hline Waste Category & Quantity Generated in 2012 (tons) & Quantity Generated in 2018 (tons) \\
\hline 6.1 Ferrous metal waste and scrap & $9,234,009$ & $9,917,644$ \\
6.2 Non-ferrous metal waste and scrap & $1,021,982$ & $1,276,126$ \\
6.3 Mixed metal wastes & 511,422 & 637,120 \\
7.1 Glass wastes & $2,462,787$ & $3,089,553$ \\
7.4 Plastic wastes & $2,781,865$ & $4,393,791$ \\
7.5 Wood wastes & $3,847,633$ & $5,253,267$ \\
12.1 Construction and demolition & $33,916,487$ & $41,265,770$ \\
wastes & $\mathbf{3 3 , 7 5 6 , 7 9 6}$ & $\mathbf{4 1 , 0 2 3 , 0 2 3}$ \\
Total CDW-non-hazardous & $\mathbf{1 5 9 , 6 9 1}$ & $\mathbf{2 4 2 , 7 4 7}$ \\
Total CDW-hazardous & &
\end{tabular}

According to Eurostat figures, at the national level 96\% of CDW were recycled in 2018 (90\% in 2012), and the amount of CDW which went to landfill was reduced to $1.7 \%$ from $2.4 \%$ in 2012 . The recycling rate has been steadily growing (Table 2) [12].

In recent years, Circular economy concept attracted an increasing attention. Its goal is to offer an alternative method of traditional dominant model of consuming natural resources. It focuses on three main approaches: reduction, re-use and recycle $[10,13]$. Many world countries are trying to decrease their construction and demolition waste by implementing various legislations and improving awareness through different measures to reduce the effects on the environment. Information is available on C\&D waste production in each part of world in relation to the recycling activities and existing policies and legislation on disposal of C\&D waste [8]. Whilst coarse recycled aggregates generated 
from construction and demolition waste are permitted by many specifications for various applications in road construction, a necessity exists for developing a high- value market for the recycled aggregate fines. Potential exist for a higher market price for recycled aggregate (RA) fines due to their residual binding properties. In fact, some RA fines possess hardening properties, such as recycled concrete aggregate, whilst others have pozzolanic properties, such as bricks and ceramic wastes. In both cases the binding capacity of these materials will significantly contribute to the cost benefits, for example by reducing the binder requirement in hydraulically bound mixtures (Figure 2) [14].

Table 2. Treatment of construction and demolition mineral waste in Italy in years 2012 and 2018 [12].

\begin{tabular}{ccc}
\hline Performed Action & Quantity in 2012 [tons] & Quantity in 2018 [tons] \\
\hline Deposit onto or into land & 919,503 & 732,347 \\
Land treatment and release into water bodies & 375 & 0 \\
Incineration/disposal (D10) & 2720 & 2188 \\
Recovery other than energy recovery -Backfilling & 160,290 & 147,623 \\
Incineration/energy recovery (R1) & 0 & 585 \\
Recovery other than energy recovery -Except backfilling & $29,782,235$ & $39,481,612$ \\
Total waste treatment & $\mathbf{3 0 , 8 6 5 , \mathbf { 1 2 3 }}$ & $\mathbf{4 0 , 3 6 4 , 3 5 5}$ \\
\hline
\end{tabular}

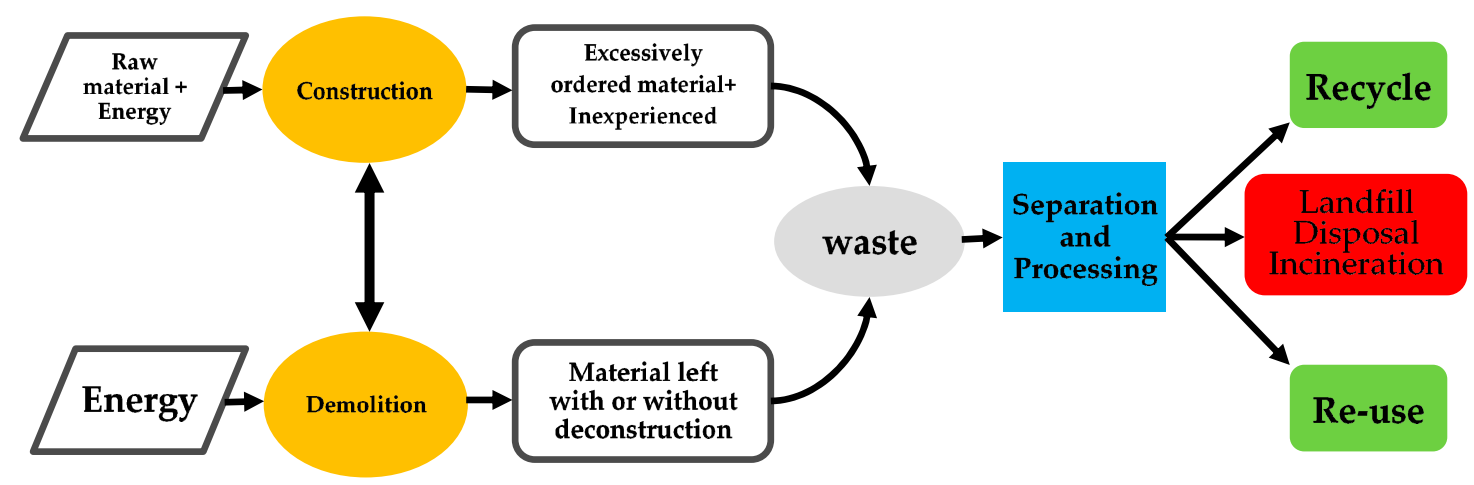

Figure 2. Circulation of construction materials from raw state to end-use and disposal [8].

\section{Main Types of CDWs}

There are three main categories of CDW aggregates: Recycled concrete aggregates (RCA), Recycled masonry aggregates (RMA, sometimes Crushed Clay Masonry-RCM) and Mixed recycled aggregates (MRA-also mixed demolition debris) $[15,16]$. However, most construction and demolition blends are combined of these types and the portion of each material can affect the properties of the total blend [17-21]. Additionally, other materials like ceramics can exist in some blends [17]. Moreover, another type of aggregate waste, reclaimed asphalt pavement (RAP) aggregate produced from crushing mixes bounded with bituminous binder, is also a typical substitute material for using in pavement and geotechnical usages $[15,22]$. The composition of CDW aggregates highly depends on their source and the processing method. The diversity of the construction operations and methods naturally mean that RA sourced from construction and demolition activities will change in quality and composition, which will definitely produce new construction materials of varying quality. Furthermore, the method of demolishing a building structure may be effective, and it could be either conventional or selective. The selective demolition approach, along with more control on the quality of the CDW materials obtained, ensures a substantial reduction of the environmental effects specifically caused by climatic change, acidification, summer smog, nitrification and release of heavy metals. These result from the emission of a wide array of compounds and elements, all of which are identified to be major pollutants [23].

Construction and demolition activities result in a wide range of materials including concrete, wood, glass, metals, as well as some harmful component. Complexity and composition of these materials make the separation of C\&D wastes a difficult mission. Some materials such as wood, 
glass and metals can be recycled directly or in few circumstances can be reused without additional processing, while, concrete waste has different features which make it unique. It is unavoidable to recycle most of waste concrete due to the large amount of natural resources being exploited for its production. This will provide a route to significant decline of the waste being directed to landfills and in parallel possibility of conserving natural resources. A major part of waste concrete is recovered in the form of RA containing attached mortar on its surfaces which brings in some of the limiting aspects of the recycling such as: increased water absorption, lesser strength and high penetration capacity of chloride [8].

Independently from the source, the overall combination of the recycled coarse aggregates are usually analyzed in accordance with the EN 933-11 standard. Different components can be often distinguished in CDW mixes (Figure 3), such as Asphalt $\left(R_{a}\right)$, Ceramics $\left(R_{b}\right)$, Cement- based materials $\left(R_{c}\right)$, Light particles $(L)$, Unbound aggregates $\left(R_{u}\right)$, Glass $\left(R_{g}\right)$, Others: wood, plastic, metal $\left(X_{o}\right)$, Gypsum $\left(X_{g}\right)[24]$.

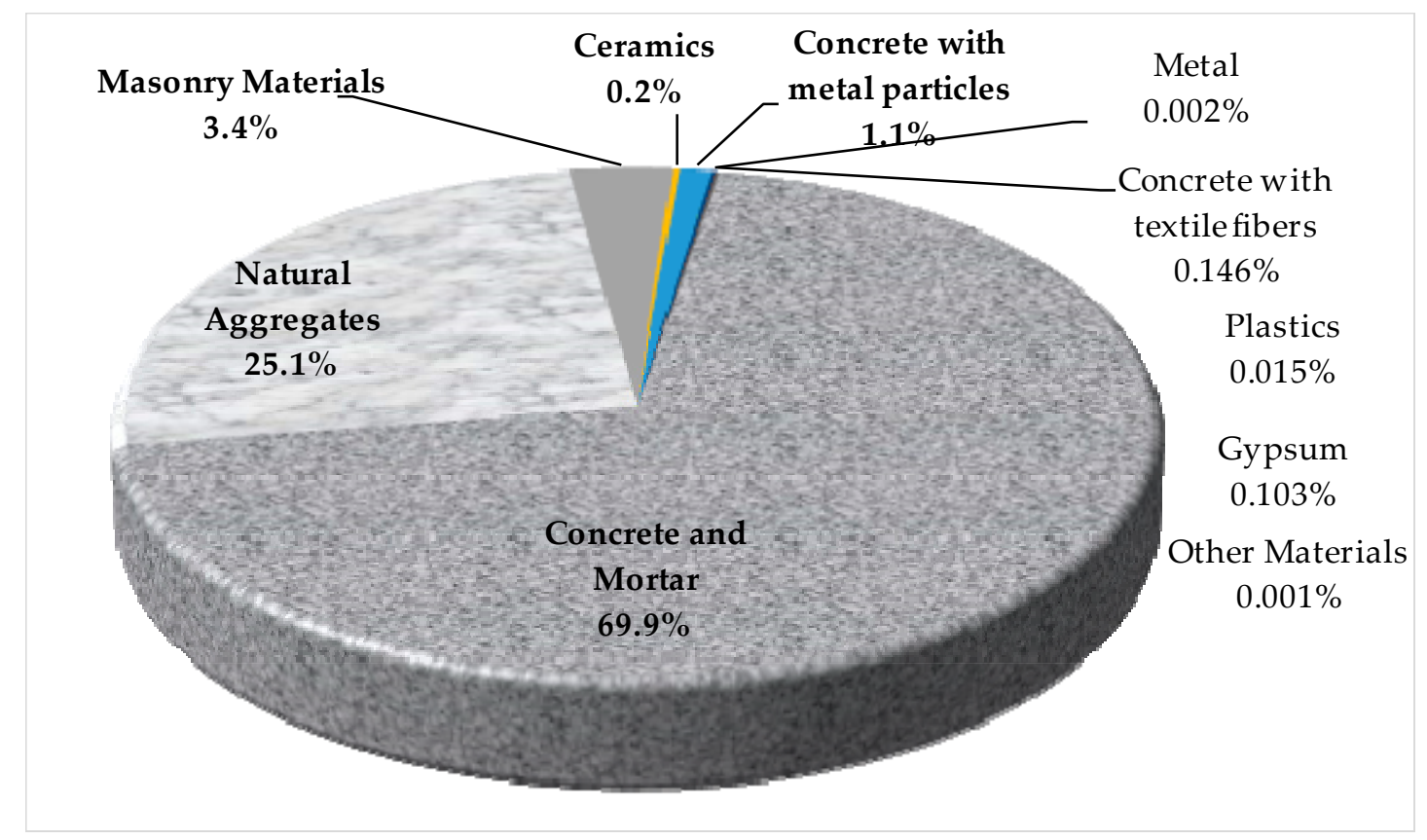

Figure 3. Example of components of recycled aggregates (\% of the total dry weight) [25].

As mentioned above, recycled concrete aggregates mostly differ from natural aggregates in that they are consisted two different parts: the natural aggregates and the attached cementitious mortar. As described, the mortar is the origin of some weak properties of the recycled aggregates: lower density higher moisture absorption, higher abrasion and sulphate content $[26,27]$. These features might have a negative effect on the recycled concrete quality, mainly influencing the material's performance linked with strain (elasticity, shrinkage, and creep, durability) and to a less degree, strength. Implemented test on aggregates for measuring the amount of adhered mortar content can be the source of discrepancy in the result: in between $25 \%$ and $70 \%$ using the treatment of samples with hydrochloric acid solution, from 25 to $65 \%$ for the making a different colored concrete, and $40-55 \%$ with thermal treatment. Furthermore, the amount of mortar attached to the fine fraction is more than for the coarse fraction. Thus, the specific gravity decreases as the percentage of coarse RA increases [27]. Finally, skid resistance might also decrease in RCA mixes because of the weak adhered paste on the surface of aggregates [4].

\section{Preliminary Characterization of CDWs}

Two main categories exist for preliminary assessments of aggregates implemented for construction of various layers of pavements: the geometrical characterization (e.g., size distribution, shape index, 
flakiness index, etc.) and the physical characterization (specific gravity, water content and freeze-thaw, etc.). Most of these characteristics can be used for the classification of the recycled aggregates which can contribute to the CE marking of the materials if European Standards are used for the tests. As for the chemical characterization of these materials, most of the local regulations require specific tests on the waste product in order to assess their potential effects on the environment. Despite this being a fundamental aspect of the recycling process, it will not be considered in this review.

\subsection{Size Distribution}

The particle size distribution (PSD) has a determining role on the mechanical properties of the recycled materials and consequently, has a major influence on the pavement structural behavior. The distribution of particles of CDW products may be different based on the source type and composition, on the procedure of demolition and on the planned application of the material. PSD is generally specified in terms of upper and lower grading limits and there are several classifications of aggregates mixes in standards based on their size range. Recycled concrete aggregates mainly have components of both gravel and sand, with a portion of fines (smaller than $75 \mu \mathrm{m}$ based on ASTM D2487, 2006) usually lower than $10 \%$. Around $75 \%$ of CDWs were crushed into the gravel fraction and the remaining in the sand fraction. Majority of the RAP batches were considered gravel as per BS 5930, relying on the considered standard [15] (Figure 4). There are several local and global standards and also technical recommendations of different institutions, which fixes the limits for the gradation of materials used in unbound layers of pavements. Moreover, there are some indexes like uniformity coefficient $\left(\mathrm{C}_{\mathrm{u}}\right)$ which give rough information about the distribution curve.

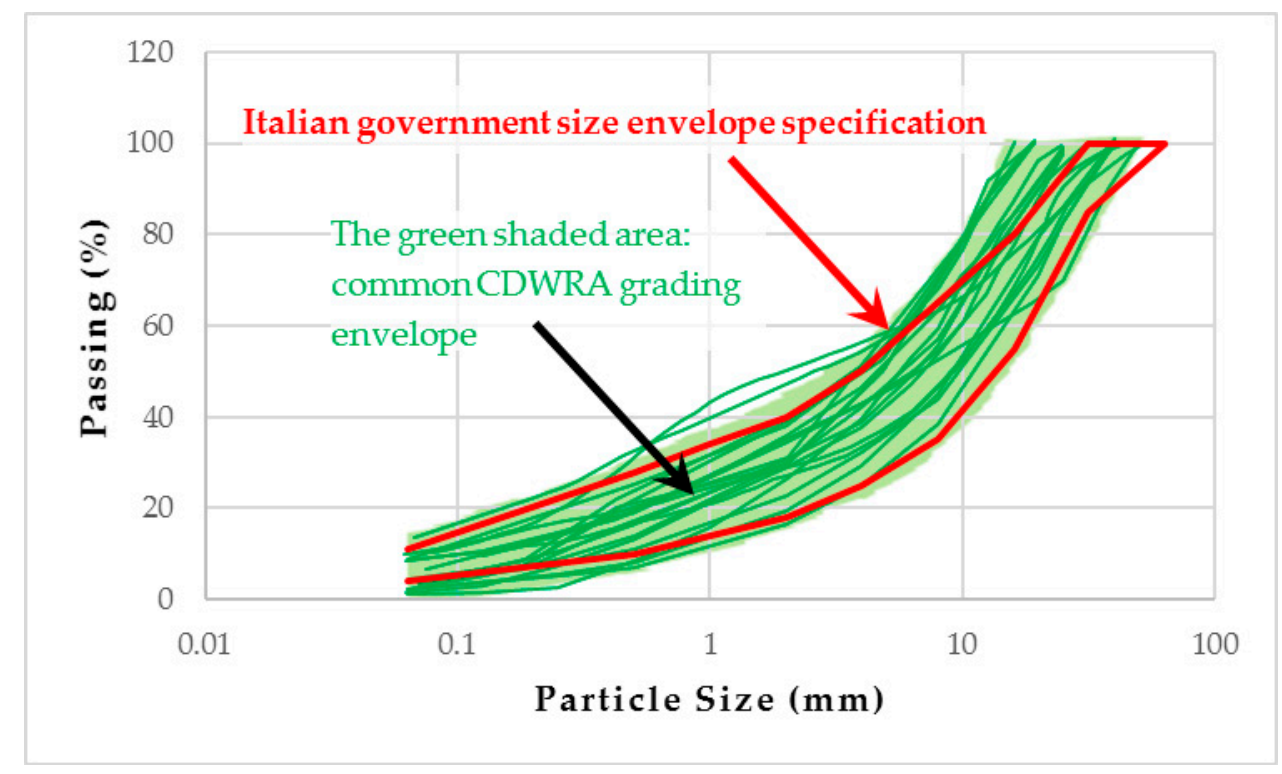

Figure 4. Particle size distribution curves of CDW recycled aggregates from previous researches [24,28-35].

\subsection{Flakiness and Shape Indexes}

Flakiness index is an indirect measure of the tendency of particles to break during compaction and under the traffic load of the service period. Some mechanical properties such as stability against permanent deformation and load -bearing capacity are linked to the resistance of particles against breaking and flaking. One of the reasons for studying the flakiness of particles can be based on the experience that, with a high proportion of such particles, handling difficulties can arise, accompanied by segregation of larger particles. Some authors tried to define the limits on particle size distribution change due to breakage with respect to the mid-size dimension. Generally, in most of the researches it 
is shown that CDW aggregates satisfy the flakiness limits [36]. Care should be taken for mixtures with high percentages of ceramic and masonry which usually have flat and elongated particles. These are also the lighter components of RA mixes. Therefore, it is not uncommon that a mixture characterized by flakiness index within the specifications limit (by weight) has a volume of flat and elongated particles higher than $50 \%$ of the total volume mixture.

The shape of a crushed particle depends on the type and condition of the equipment used to carry out the crushing and on the nature of the original rock, as well as on other variables related to the age of the material and its exposure to climate. In general, a high shear strength mixture is achieved with highly angular stones. There are different methods for specifying particles shape, using words such as "cubic" or "angular" or some methods based on the percentage of crushed faces of particles. It is known that an angular material will tend to have a high angle of internal friction (and therefore a high stress ratio at failure). Angularity is not a property which is readily quantified. Most methodologies rely on description and visual categorization as counting of apexes or faces is possible, but this takes no real account of the sharpness of the edges between faces and therefore cannot be relied upon to give a consistent measure [37]. Shape index is rarely studied in CDW recycling. As an example, Cerni and Colagrande have found a value of $28 \%$ as shape index for CDW aggregates [31]. Cardoso et al. declared that, independent of the volume decreasing of previous mortar, two or more crushing stages typically lead to rounder and less sharp particles; if RCA only applied an initial crushing process, they will usually show higher shape and flakiness indexes than natural aggregates [16].

Some studies have worked on the changing of particle shapes during Los Angeles abrasion test and Proctor test. Leite et al. showed that despite the fact that cubic grains represented the majority in the cementitious materials, flat and elongated CDW aggregates change to cubic particles after both intermediate and modified Proctor impulse compaction. It is also stated that most of the breakages occur on the coarse fraction at the initial stages of compaction, when the material is not yet densified and the mobility of the particles is facilitated [34]. Moreover, It was shown that presence of ceramic would increase the flakiness and the flakiness index of the batches consisting totally from ceramic rubble could reach up to 40, which is more than most of the limit values [24]. The results of flakiness index for construction and demolition waste considered in different publications are shown in Table 3.

Table 3. Flakiness index values for CDW aggregates.

\begin{tabular}{ccc}
\hline Researcher & Reference & Flakiness Index (\%) \\
\hline Barbudo et al. & {$[17]$} & 15 \\
Silvia et al. & {$[21]$} & $8-30$ \\
Vegas et al. & {$[24]$} & $9-40$ \\
Cerni and Colagrande & {$[31]$} & 26.5 \\
Jiminez et al. & {$[38]$} & $8-19$ \\
Morafa et al. & {$[39]$} & $12-20$ \\
Nataatmadja and Tan & {$[40]$} & $6-14$ \\
Gómez-Meijide and Pérez & {$[33]$} & 4.5 \\
Del Rey et al. & {$[35]$} & $12.8-24$ \\
Herrador & {$[30]$} & 12 \\
\hline
\end{tabular}

\subsection{Specific Gravity}

The specific gravity of natural materials commonly used in geotechnical and paving applications can vary depending on the material type and it ranges between 2.60 and 2.75 or more on average. As well as in various calculations of soil mechanics, physical specifications like porosity, void ratio and weight- volume ratio, are determined by the specific gravity of materials. The average specific gravity of RCAs is relatively higher than that of the other types of recycled aggregates. Lower specific gravity of RA is essentially due to the presence of: (1) adhered cement mortar and its porous nature; (2) bitumen coating (in RAP) which has a density value normally lower than $1.10 \mathrm{~kg} / \mathrm{m}^{3}$; or (3) containing masonry 
and lightweight materials (in CDW) [15]. The results and values of specific gravities for construction and demolition waste considered in different publications are shown in Table 4.

Table 4. Specific gravity values for CDW aggregates.

\begin{tabular}{ccc}
\hline Researcher & Reference & Specific Gravity $\left.\mathbf{( g r} / \mathbf{c m}^{\mathbf{3}}\right)$ \\
\hline Barbudo et al. & {$[17]$} & 2.240 \\
Herrador et al. & {$[30]$} & 2.040 \\
T. Park & {$[41]$} & 2.533 \\
Poon and Chan & {$[42]$} & 2.380 \\
Gabr and Cameron & {$[43]$} & 2.575 \\
Tahmoorian et al. & {$[44]$} & 2.370 \\
Agrela et al. & {$[45]$} & 2.340 \\
Tahmoorian et al. & {$[46]$} & 2.408 \\
\hline
\end{tabular}

\section{Geotechnical and Mechanical Characteristics}

\subsection{Compactability}

Some engineering properties of soil or other unbound paving materials, such as shear strength, internal friction and water drainage improve by reducing the volumetric ratio between the voids and the particles due to rearranging and repacking of grains with mechanical compaction. Several types of assessments such as standard Proctor and modified Proctor tests are used to evaluate the compactability of soils. The goal is to determine the optimum moisture content (OMC) at which soils or mixtures of aggregates mixes attain the densest condition, demonstrating their Proctor Maximum Dry Density (MDD). Differences between these test procedures include the weight of the hammer used ( $2.7 \mathrm{~kg}$ for standard proctor and $4.9 \mathrm{~kg}$ for modified proctor) and the falling height of the hammer (35 and $45 \mathrm{~cm}$ ) [15].

The final outcome of the compactability test is the moisture -dry density curve. The moisture -density curves are in fact a presentation of the sensitivity of the density with respect to the change in moisture content for the materials [47]. Typical curves are shown in Figure 5. Materials with flat curves can tolerate a greater amount of variation in the moisture content without compromising much of the achieved density. On the other hand, during compaction, moisture content of materials having sharp curves which are sensitive to the change in moisture should be close to the optimum value [42].

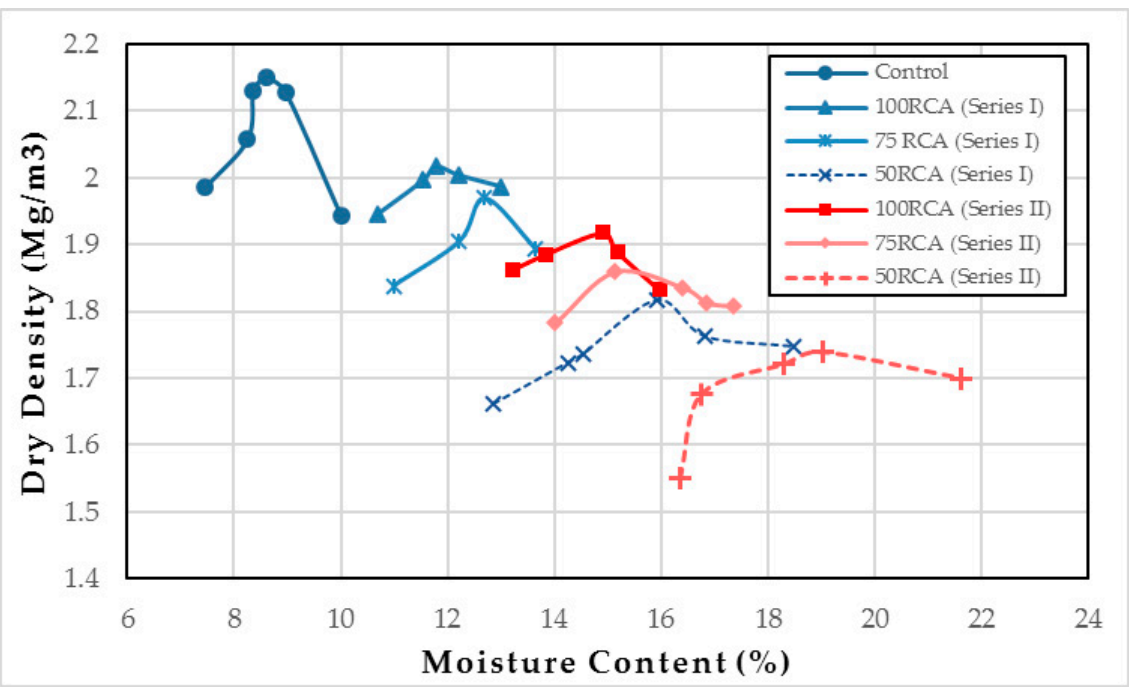

Figure 5. Moisture- dry density for blends with different percentages of crushed clay bricks and recycled concrete aggregates. Serie I has recycled concrete aggregate as fine aggregate and Serie II has crushed clay brick as fine aggregate [42]. 
Generally, recycled aggregates have comparatively higher water absorption due to the attached adhered cement mortar on RA, or the porous character of the aggregates such as clay bricks. This causes an increase in OMC which is greater than $10 \%$ for most of the RAs, those of recycled masonry aggregates and mixed recycled aggregates being relatively higher than that of RCA [15]. A pre-wetting process might be considered for the assessment of compactability of these materials.

Moisture and dry density are directly influenced by type and combination of CDW aggregates. Poon and Chan in 2006 clearly demonstrated that by substituting the recycled concrete aggregates with crushed brick, the optimum moisture increases while the MDD decreases linearly (Figure 5) [42]. Leite et al. evaluated the compaction of CDW aggregates by standard and modified Proctors. The standard effort corresponds approximately to $50 \%$ of the modified effort and it is used for sub-bases in some countries like Brazil. Authors reported the values of $13.5 \%$ for optimum moisture content and $18.2 \mathrm{kN} / \mathrm{m}^{3}$ for maximum dry density for the modified proctor test, and $14.6 \%$ and $17.6 \mathrm{kN} / \mathrm{m}^{-3}$ for standard Proctor test [34]. The values of Proctor test for different studies on CDWs are shown in Table 5.

Table 5. Compactability test results from literature review.

\begin{tabular}{|c|c|c|c|}
\hline Researcher & Reference & OMC & $\operatorname{MDD}\left(\mathrm{kg} / \mathrm{m}^{3}\right)$ \\
\hline Barbudo et al. & [17] & $11.6 \%$ & 1950 \\
\hline Arulrajah et al. & [19] & $10.7 \%$ (Brick dominant) & 1982 \\
\hline Vegas et al. & [24] & $6.52 \%$ & 1885 \\
\hline \multirow{2}{*}{ Leite et al. } & \multirow{2}{*}{ [34] } & 13.5\% (Modified) & 1820 (Modified) \\
\hline & & $14.6 \%$ (Standard) & 1760 (Standard) \\
\hline Jimenez et al. & [38] & $12.7 \%$ & 1910 \\
\hline Morafa et al. & [39] & $12.5 \%$ & 1940 \\
\hline Herrador et. al. & [30] & $9.4 \%$ & 2040 \\
\hline Agrela et. al. & [45] & $11.5 \%-12.4 \%$ & 1960-1990 \\
\hline Arisha et. al. & [28] & $12.7 \%$ & 1860 \\
\hline Jimenez et. al. & [32] & $12.3 \%$ & 1855 \\
\hline Rahman et. al. & [48] & $12.5 \%$ & 2100 \\
\hline Azam and Cameron & [49] & $11.6 \%-12.5 \%$ & 1857-1919 \\
\hline
\end{tabular}

\subsection{California Bearing Ratio}

California Bearing Ratio (CBR) is widely used for characterizing subgrade, subbase and base materials of pavements. It has been associated with pavement service behavior and design methods and it has been at the basis of several airfield pavement design methods. Considered reasonable and sound, it could be assessed using simple test equipment in the laboratory or in the field and at moisture -density conditions existing under the pavements [50]. Some authors pose doubts on the test's relevance and usefulness because of the difficulty in producing a sample in a mold with a 152-mm diameter at the same conditions expected in the field [51]. The CBR test is usually done in two different modes of un-soaked and soaked (by immersion) in water. Several standards are available for the testing procedure, one European standard (EN 13286-47), two American (AASHTO T193-72 equal to ASTM D1883) and one English (BS 1377).

Vegas et al. reported a range of $76-130 \%$ for different batches of CDW aggregates tested in different collection times after 4 days of immersion. These values improved by increasing the time of soaking in the water up to 90 days to the range of $138-185 \%$, which could be because of remaining binding potential of the cement in the crushed concrete (Figure 6) [24]. By evaluating the relation between dry density, moisture content and CBR value, O'Mahony showed that for equivalent dry densities, the CBR index decreases by increasing the moisture content [51]. Barbudo et al. measured the California Bearing Ratio for different types of mixes with different compounds, compacted by modified Proctor in their optimum moisture content, in order to evaluate the influence of different crushing and screening methods, as well as of the mix proportions on the bearing capacity. After 4 days of soaking in water, recycled concrete aggregates showed a CBR index of 55-138\%, with an average of $100 \%$ while different 
mixtures of concrete and brick fell in the range of $40-110 \%$, with an average of 74 . This means that concrete aggregates can reach higher bearing capacity than mixed batches [17]. Leite et al. reported $73 \%$ and $117 \%$ for CBR values of standard and modified compaction mixes of CDW aggregates [34]. Arisha et al. reported CBRs of around $160 \%$ for mixed aggregates, which dropped to almost half for recycled masonry aggregates. This could be related to the content of residual free lime in CDW mixes and the cementation process [28]. Morafa et al. showed that for oil- contaminated RCA aggregates, there is a limit value of contaminants corresponding to the maximum CBR and density. CBR was measured in a range of $72-85 \%$ for four oil-contaminated concrete aggregates [39]. Gabr and Cameron tried to implement an experimental relation between CBR index, and the moisture content of 4-day soaked samples; increasing density and CBR results were reported by increasing moisture content in all recycled materials. Recorded values are in the ranges of $90-143 \%$ and $120-215 \%$ for two kinds of Australian CDW aggregates [43]. Jiménez showed that recycled concrete aggregates after soaking for 4 days, exhibit CBR values between those of natural aggregates and mixed debris. CBR values in the range of $97-137 \%$ are reported by the authors [52]. These results are shown in Table 6 along with some other data.

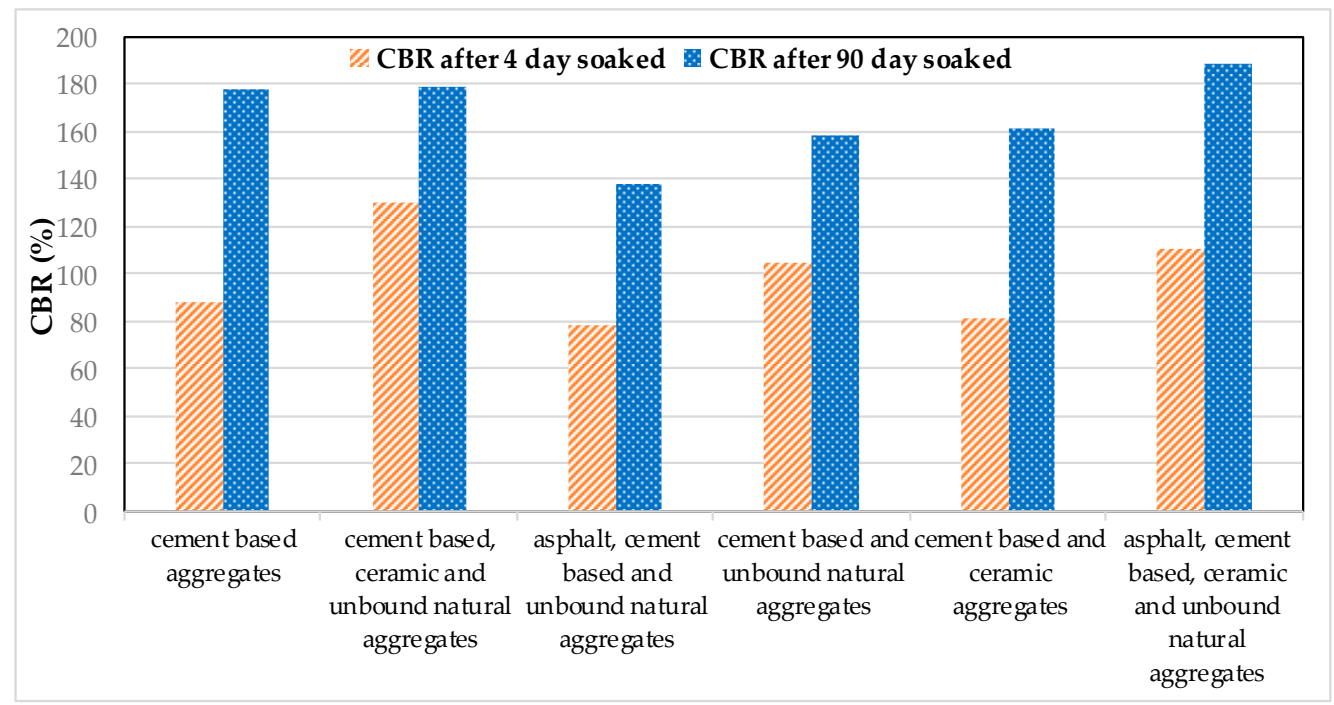

Figure 6. CBR development for different types of Construction and Demolition mixed recycled aggregates after 4 and 90 days of immersion in water, based on the various combination of compounds [24].

Table 6. Literature results of California Bearing Ratio test for different CDW materials.

\begin{tabular}{cccccc}
\hline \multirow{2}{*}{ Researcher } & \multirow{2}{*}{ Reference } & \multicolumn{2}{c}{ Standard Proctor } & \multicolumn{2}{c}{ Modified Proctor } \\
\cline { 3 - 6 } & & Soaked & Unsoaked & Soaked & Unsoaked \\
\hline Jiménez et al. & {$[17]$} & - & - & $74 \%$ (mean) & - \\
Vegas et al. & {$[24]$} & - & - & $76-197 \%$ & - \\
Cerni and & {$[31]$} & - & $90 \%$ & - & - \\
Colagrande & {$[34]$} & - & $73 \%$ & - & $117 \%$ \\
Leite et al. & {$[38]$} & - & - & $68 \%$ & - \\
Jiménez et al. & {$[39]$} & - & - & - & $72-85 \%$ \\
Morafa et al. & {$[35]$} & - & - & - & $63.7 \%, 67.3 \%$ \\
Jiménez et al. & {$[42]$} & $35-62 \%$ & $-62 \%$ & - & - \\
Poon and Chan & {$[43]$} & - & - & $70-215 \%$ & - \\
Gabr and & {$[28]$} & - & - & $62-94 \%$ & - \\
Cameron & {$[32]$} & - & $71-115 \%$ & - & - \\
Arisha et al. & {$[53]$} & $35-113 \%$ & & & - \\
Jiménez et al. & & & & - & - \\
Lanciere et al. & & & & &
\end{tabular}




\subsection{Abrasion}

Los Angeles Abrasion (LAA) is used to determine the resistance of aggregate to fragmentation or mechanical breakdown because of impact and wearing [15]. Tests in a ball mill known as Los Angeles drum (EN 1097-2) produce a combination of abrasion and crushing, while a micro-Deval test (EN 1097-1) causes only abrasion. In all abrasion tests a certain fraction of the material is exposed to wear and the resulting increase in fines content is measured. For determining the impact strength of the aggregates, the alternative standardized impact test (EN 1097-2) is implemented. The European Los Angeles test is a modification of the original test method used since the 1920s. In the most recent standard five kilos of the $10-14 \mathrm{~mm}$ fraction of the material is exposed to 500 rotations in a steel drum together with 11 steel balls.

Aydan et al. showed that weight loss in LAA decreases from $31 \%$ to $24 \%$ as the substitution ratio of RCA with NA increases from zero to $100 \%$ and natural aggregates are stronger in opposing to impact forces in comparison to RCA [54]. Furthermore, in a similar study, Diagne et al. showed that in the CDW aggregates, resistance to abrasion differs by the portion of recycled concrete aggregates (RCA) and recycled clay bricks (RCB). The RCAs have a LAA index of $30 \%$ which increases to 36.8 for the mixture composed of $100 \%$ of RCB [20]. Barbudo et al. also measured the LAA for natural, concrete recycled and mix recycled aggregates, and showed that mixed recycled aggregates and concrete recycled aggregates have less resistance to abrasion, with average Los Angeles values of $38 \%$ and $33 \%$, compared to the natural aggregate LAA coefficient of $21 \%$ [17]. Arisha et al. measured the very low value of $83 \%$ for LAA of masonry recycled aggregates, which is out of all requirements for utilization of recycled materials. This measure is much better for mix of CDW aggregates, with the LAA result of $47 \%$ [28]. Morafa evaluated the aggregates recycled from oil- contaminated concrete waste and showed that the abrasion of RCAs (27\%) is much more than virgin natural aggregates $(18 \%)$, and also the soundness of aggregates could affect the LAA results [39]. Jimenez tried to figure out a relation between particle size and Los Angeles abrasion loss (Figure 7). They tried to prove that the higher is the Los Angeles coefficient, the higher the mean particle size is. A loss of $34 \%$ for LAA of recycled concrete aggregates and the range of $31-41 \%$ for mixed debris of construction and demolition were measured, which both are higher than the loss for natural aggregates (20\%) [32].

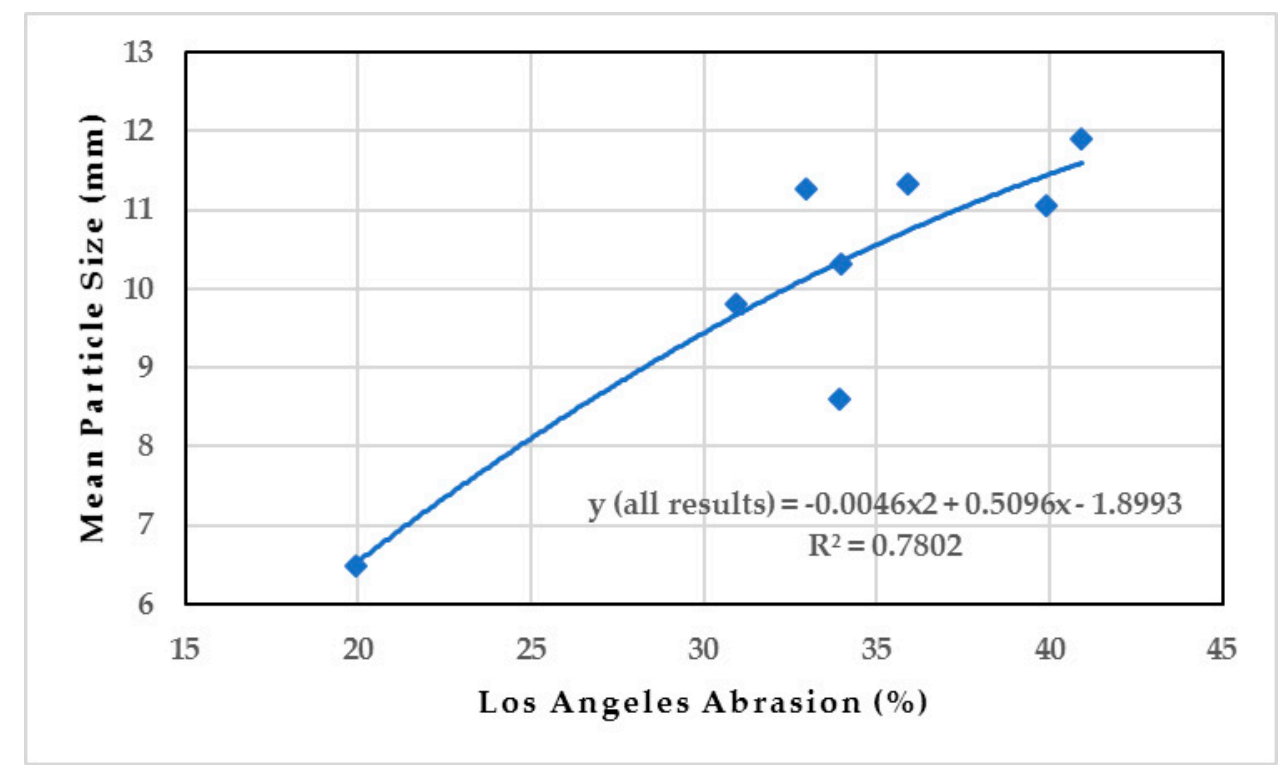

Figure 7. Mean particle size vs. Los Angeles abrasion [32].

De Juan tried to find a relation between the attached mortar and the LAA abrasion rate (Figure 8) assuming that in the Los Angeles abrasion test all the adhered paste of recycled aggregate become 
powdered, apart from the abrasion induced by the natural aggregate. For this reason, both properties are expected to be correlated. The measured values for Los Angeles loss are in the range of $36-42 \%$ for fine aggregates $(4 / 8 \mathrm{~mm})[26]$.

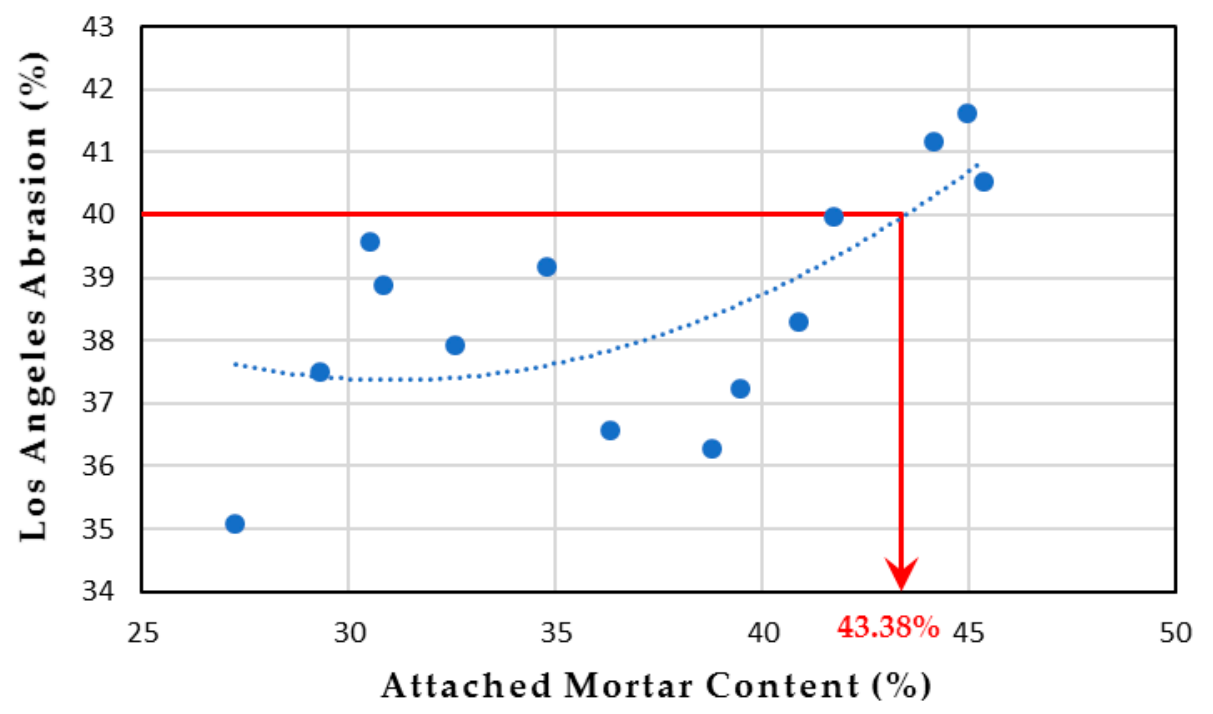

Figure 8. Attached mortar vs. Los Angeles abrasion; 43.38 is the proposed maximum percentage of attached mortar referred to the limit of $40 \%$ abrasion [26].

\subsection{Resilient Modulus}

Pavements are structures which are subjected to large numbers of repeated loads. The resilient modulus of unbound materials represents their stiffness (stress-strain relationship) under repeated loads that resemble traffic loads. It is commonly known that the resilient modulus depicts the attributes of aggregates, such as particle size distribution, density and moisture content, as well as applied factors such as stress and to a lower extent, temperature [15]. Together with CBR test, triaxial compaction test for measuring the resilient modulus is also one of the major material evaluations for various layers of pavements, especially for evaluating the behavior of pavement material under cyclic traffic loads. Although the same compaction energy was utilized in both tests, some facts and disadvantages of CBR may have contributed to the increased observed result could be counted as: First; specimens of CBR test may not be properly representative of the original material as the specimens of resilient modulus. There is a limitation for maximum aggregates size in CBR standard procedure, but the resilient modulus allows the use of the same gradation used in the field. Secondly; the confining stress in the CBR test is not demonstrative of the observed confining stress of the field as the one imposed in the resilient modulus. Thirdly, the measured displacements in the resilient modulus test are in the elastic zone, but this is not observed in the CBR [34].

The main challenge in studying and comparing the resilient modulus is its dependence on the stress condition. The value of the resilient modulus in unbound granular materials is a result of the confining stress level and deviatoric stress. In particular, it is usually possible to obtain the experimental parameter $\left(\mathrm{M}_{\mathrm{r}}\right)$ related to each pair of tension $\left(\sigma_{3}, \sigma_{\mathrm{d}}\right)$ investigated. One of the most used models for resilient modulus of granular materials is the K- $\theta$ model $\left(M_{r}=K_{1} \times \theta^{K 2}\right)$, which describes the resilient modulus by an exponential function of sum of principal stresses by a good approximation [55]. Generally, the stiffness stated by the resilient modulus growths as the bulk stress increases. Actually, a rise of $\theta$ causes the grains which make the material solid structure to become closer to each other and, consequently, it raises the interlocking degree and the contact areas among them with the consequent reduction of the specimen deformability. Considering an element of soil under the road pavement, the confinement pressure influencing it is the outcome of horizontal compression and contact stress produced by adjacent material and it is a function of the depth. In the altogether, since in 
recycled materials the stiffness increases remarkably with the confining pressure, it is advisable to use these materials in lower layers. Cerni and Colagrande are convinced that it is reasonable to use a CDW-RA mixture in a lower layer such as the road subbase, where the low vertical loads generated by vehicles do not cause technical necessities and economically convenience for the application of elevated performance, very expensive material. Moreover, the same authors demonstrated that the CDW-RA mixture, even characterized by the presence of minor amounts of binding agents which add cohesive properties to it (such as lime), presented a resilient behavior very close to a common frictional material like a virgin quarry aggregate mixture. The characteristic which proposed such a similarity is low susceptibility to water [31]. Azam and Cameron demonstrated that adding recycled masonry aggregates to recycled concrete aggregates will decrease their resilient modulus and increase the permanent strain of the mixes under triaxial repeated test. Moreover, the moisture content has an important effect on the resilient properties of the mix materials, and a reduction in resilient modulus can occur with an elevation in moisture content. The authors also evaluated the relation between the resilient modulus and matric suction which happens because of the capillary nature of water between aggregates and they identified a simple power model which adequately fits the data between matric suction and the resilient modulus in a single stress stage [49].

Cameron and Azam in their research, mainly investigated the effect of relative moisture content on the resilient modulus of different blends of RCA and recycled masonry aggregates. As shown in Figure 9, an important decrease in resilient modulus happened with an increase in moisture content which becomes steady after reaching $80 \%$ of the OMC. The effect of masonry portion on resilient modulus was sensibly clear with a reduction in resilient modulus as the crushed masonry ratio increased [18]. The results of the K- $\theta$ model for some completed research on CDW aggregates are shown in Table 7.

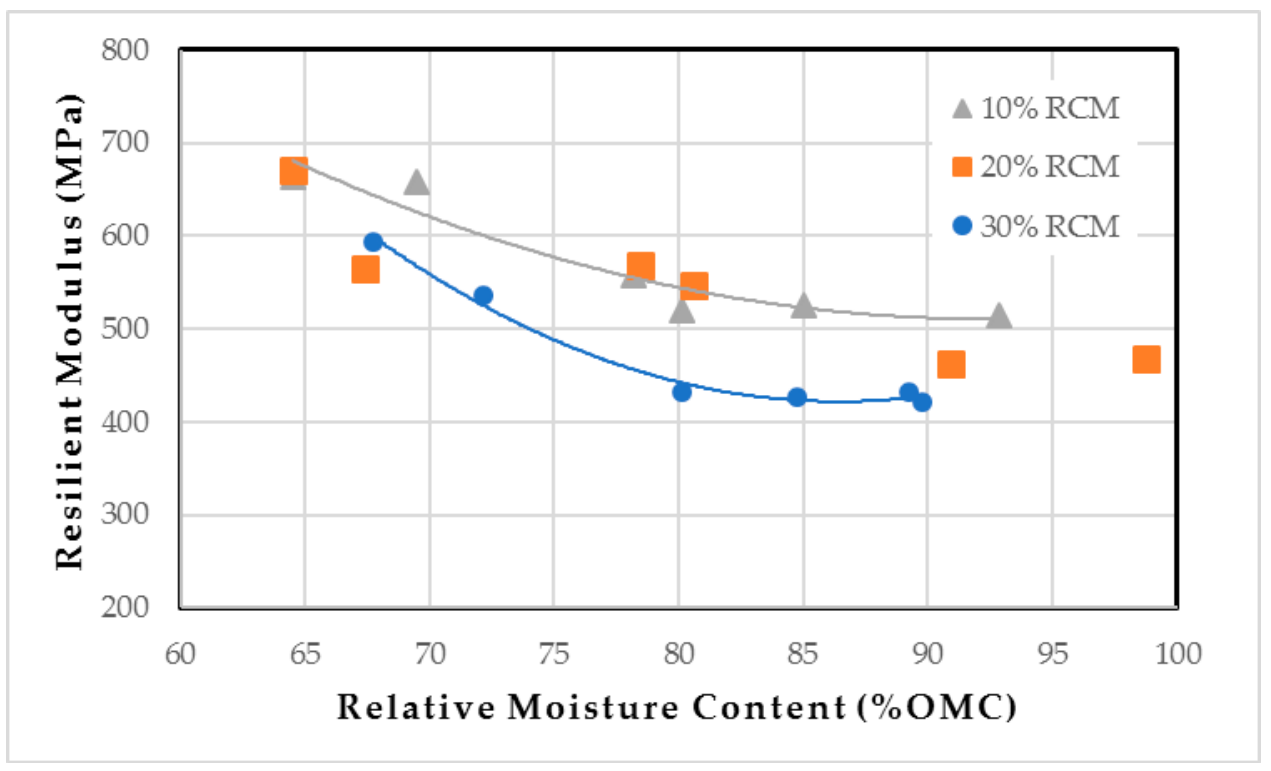

Figure 9. Resilient modulus change by changing relative moisture content in different mixtures of CDWRA [18].

Table 7. Parameters for the modelling the resilient modulus.

\begin{tabular}{ccccc}
\hline Researcher & Reference & Material & $\mathbf{K}_{\mathbf{1}} \mathbf{( k P a )}$ & $\mathbf{K}_{\mathbf{2}}$ \\
\hline Arisha et al. & {$[28]$} & CDW-RA & 15.48 & 0.54 \\
Cerni and Colagrande & {$[31]$} & CDW-RA & $3.8-5$ & $0.60-0.64$ \\
Leite et al. & {$[34]$} & CDW-RA & $4.4-5$ & $0.42-0.46$ \\
Nataatmadja and Tan & {$[40]$} & RCA & $14.3-16.7$ & $0.55-0.60$ \\
\hline
\end{tabular}


One of the properties which are usually studied together with the resilient behavior, is the development of permanent strain under repeated load and the shakedown (maximum ratio of deviatoric stress to confining stress) limit. This aspect has less importance when studying the low volume or rural road pavements, as the deterioration of low volume roads has less priority compared with other parameters. However, due to the heavy loads that can be applied on rural and farm roads because of the traffic of agriculture equipment and the actual pavement structure thickness, this parameter should be taken into consideration. This should be done in order not to reach the limit of uncontrolled increasing plastic strain of unbound layers in the initial stages of the pavement service, as the rate of plastic deformation could accelerate resulting in fast breakdown of the unbound layer.

Leite et al. studied the shakedown limit in different stress conditions for CDW-RA. The fact that permanent deformation of the CDW layers related to the stress levels must be extremely considered in the case of base layer designing, particularly when a thin asphalt surfacing is exerted, due to the usual high stress levels transferred to the base. Considering the shakedown concept leads to the realizing of the material behavior under traffic loading and to neutralize those pavement damages. It was shown that for a $\sigma_{\mathrm{d}} / \sigma_{3}$ limit transition from 4 to 6.7 , the rate of deformation increases visibly, which should be considered in the design of rural and farm roads for avoiding the degradation of their unbound layers at initial stages of their service [34].

\section{Examples of Specific Uses in Unbound Layers of Pavements}

The use of construction and demolition waste recycled aggregates (CDW-RA) as a replacement for natural aggregates (NA) in the pavement construction industry is by far the most common application, if compared to their use in the construction of buildings and geotechnical applications. However, within the pavement construction applications, RAs tend to be mainly used in the unbound form and more often in sub-base and base layers and less in hydraulically bound and bituminous bound mixtures [56]. Figure 10 illustrates the most common steps leading from the collection of the CDW materials at the recycling plant, to their management, classification and use in an unbound layer of a pavement.

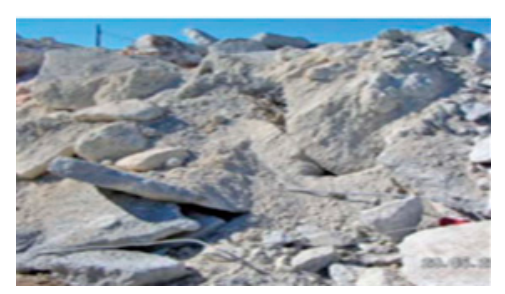

(a)

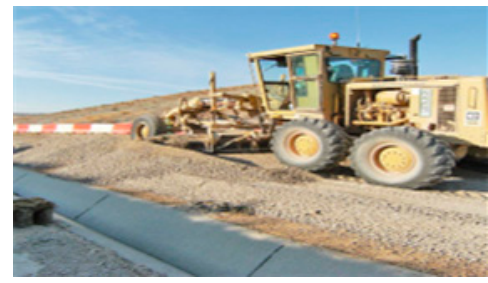

(d)

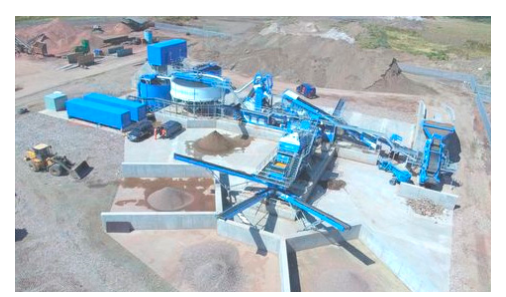

(b)

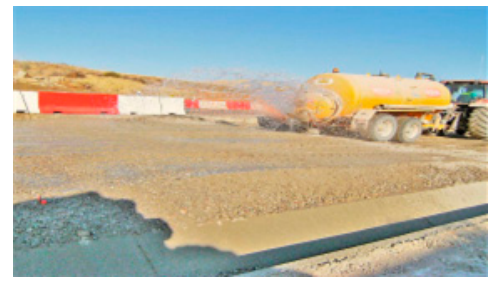

(e)

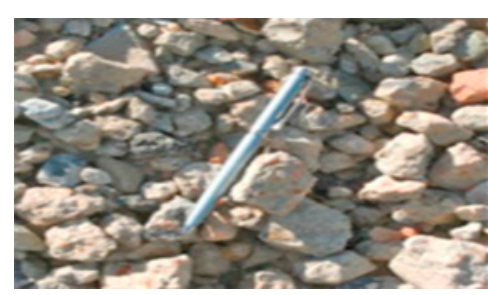

(c)

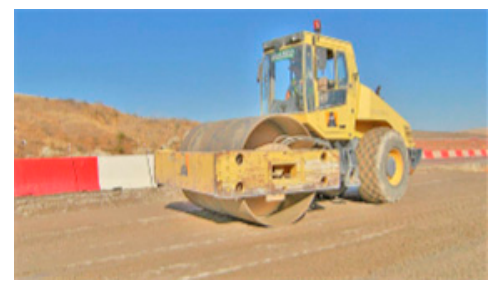

$(\mathbf{f})$

Figure 10. Common steps for the construction of a road pavement with CDW aggregates: (a) initial waste material; (b) Grinding and classification of various components in a fixed plant (credit: Brewster Bros); (c) CDW final product; (e) spreading and layering; (e) moisture control and (f) compaction [30,57].

In 2006, Lancieri et al. studied the performance of roads built by using CDW aggregates by means of the Falling Weight Deflectometer (FWD). Authors tested the unbound low traffic road pavement approximately 4 and 8 years after construction. An improvement in the structural behavior of the layer was observed and was attributed to the self-cementing properties of the adopted CDW materials. 
These field experiments were combined with laboratory tests completed in order to study the time change of mechanical features of C\&D materials and to assess the effect of compaction methods on the enhancement of resistance recorded with the gyratory compactor. The obtained data and results confirm that road construction could propose a reliable application for $C \& D$ waste recycling. It was proved that the E-moduli back-calculated by analyzing the FWD tests, showed a meaningful improvement after 4 and 8 years of traffic, which could be also due to further compaction during traffic. However, the layers built with materials obtained from recycled construction and demolition waste were shown to keep over time a performance that was by no means lower to that of traditional materials. Besides, results both of in-situ and laboratory tests discovered that the load-bearing capacity of the material had substantial sensitivity to the dry density ratio [53].

Herrador et al. constructed a test road section of $80 \mathrm{~m}$ in length made with recycled CDW aggregates and designed for a mean daily traffic of 100-199 commercial vehicles per day. The authors also showed that the compaction of the artificial CDW aggregate at the field is more difficult because it needs more water. FWD test showed very satisfying results in terms of load- bearing capacity of CDW layers. Moreover, a simple cost analysis was done by comparing the manufacturing costs of both CDW aggregates and natural aggregates: the cost of the recycled aggregates was higher than the natural ones. The difference in price origins from the fact that the cost of waste cleaning and management is added to the total price of recycled aggregate $(2.35 € / t)$. This is more costly than blasting with explosives $(1.47 € / t)$, which is a necessary budget item in the cost of natural aggregates [30].

Leek et al. studied the performance of three test road sections made of CDW in Western Australia, comparing them with sections made of natural aggregates. This research proved that recycled roadbase aggregates obtained from recycled demolition materials can offer a good quality and high strength base for roads, which can allow increased asphalt fatigue life, because of the reduced deformations. According to the authors, the source of recycled concrete can have a substantial effect on the material rehydration and its possible further excessive stiffness that could cause block cracking. It is suggested that adding masonry, tile and or sand as a fine material into the recycled product may control the excess of stiffness and limit the effects of rehydration, which may not be sufficiently captured by a 28-day unconfined compressive strength test [58].

Jiménez et al. studied the performance of the unbound base layers of two experimental unpaved rural road sections constructed with selected CDW materials. The external factors such as climate and traffic were also considered in the research and the bearing capacity was studied using the plate load test (PLT). It was shown that the change in dry density of layers within the first year is neglectable. It was also seen that vehicle traffic could improve the bearing capacity of CDW unbound layers after some years, which could be attributed to the moisture increase or to the pozzolanic activity in the attached cement mortar of aggregates. The only drawback connected to the use of CDW materials in pavements was identified to be the soluble salt content. All tests of static PLT, FWD and Roughness exhibited excellent engineering properties and these properties were maintained during several years of service under traffic load. As a general conclusion of their research the authors were satisfied with the use of CDW for unpaved rural roads [38].

Del Rey et al. tried to study the use of unbound CDW in subbase and base layers of unpaved rural roads and evaluated the behavior of mixed CDW aggregates with respect to natural aggregates. The density of field layers and moisture content were measured using nuclear density equipment during construction of three test sections. Moreover, static plate load tests were implemented to prepare the load-strain curves and Falling Weight Deflectometer measurements recorded the strain observed at the surface as the result of the dynamic load. Additionally, the degradation of the road pavement was assessed by means of measuring the rut's depth at the surface. It was shown that the average deflection values obtained in the trial sections constructed using CDW aggregates were $63 \%$ and $46 \%$ higher than those obtained in the section made with natural aggregates. According to the authors, this meant that using CDW aggregates in the subbase would need a stiffer subgrade in order to reach a bearing capacity falling in the acceptable range. A reduction in the elastic modulus was experienced 
in the section constructed with CDW, which was linked to the low fragmentation resistance of the material. Although CDW underwent higher deformation and had less elastic modulus values than NA, the CDW aggregates used in this study showed an acceptable performance. Overall, the results of the study suggested that CDW aggregates can be utilized in structural layers of low traffic unpaved roads, constructed over subgrades of expansive clays. The authors concluded by recommending the use of CDW in unpaved rural roads with low traffic [35].

\section{Conclusions}

The number of completed and on-going studies on the possible use of CDWs has increased in the recent years and this gives evidence of the diffuse concern on the sustainability of the construction sectors. In many cases CDW have been proven to perform as well as natural aggregates and in some cases, the residual binding properties have contributed to the development of mechanical properties in time. The use of CDWs in pavements is more likely one of their best applications as their adoption can be calibrated on the basis of their actual laboratory and field assessed characteristics. In most of the cases their constituents are natural aggregates, and this is usually positive for their use as unbound layers.

The experimental methods to characterize the recycled C\&D waste materials are the same as those adopted for natural aggregates. Among them, compactability, bearing capacity, abrasion and resilient modulus are usually given priority as their data can be easily considered for technical specifications and in the design processes of pavements.

In rural roads and agricultural paved areas traffic is normally made of slow machinery with large tires and relatively high loads. Surface characteristics such as roughness and skid resistance are in most cases not considered as a design feature and the main concerns are referred to permanent deformations and bearing capacity, especially in the wet seasons and on clayey soils. For the same pavements, the possible change in gradation due to the weaknesses in abrasion of the CDWs can be a minor concern if the two above characteristics are guaranteed. The simplest use of recycled CDWs in rural pavements is as material for a unique top and thick layer placed on the existing soils. According to the research findings in the literature, the main design aspect to focus on should be the actual bearing capacity of the subgrade soils in different moisture conditions. The use of coarser mixes and/or of separation geosynthetics can be a viable solution to maintain the pavement bearing capacity within the limit range.

Once the waste materials have been treated at the recycling plant and the CDW aggregates can return on the market as recycled construction material, their use in pavement layers does not differ from that of natural aggregates. The construction steps are the same and the same machinery can be used for the delivery, laying, grading and compaction of the layers. This is valid for both unbound and bound materials, including the possible application for bituminous layers.

In conclusion, the use of CDWs in the construction of pavements has proven to be a viable solution to exploit their residual positive properties. The recycling processes and the correct classification and selection of the raw waste materials is of great importance in the quality of the final product, i.e. of the constructed layers. Minor additional caution should be used when their use is foreseen in foundation or base layers.

Author Contributions: Conceptualization, C.S. and S.P.; resources, C.S., D.T. and P.T.; writing-original draft preparation, S.P.; writing-review and editing, C.S., S.P. and D.T.; visualization, S.P.; supervision, C.S., All authors have read and agreed to the published version of the manuscript.

Funding: This research received no external funding.

Conflicts of Interest: The authors declare no conflict of interest. 


\section{References}

1. Nwakaire, C.M.; Yap, S.P.; Onn, C.C.; Yuen, C.W.; Ibrahim, H.A.; Maduabuchukwu Nwakaire, C.; Poh Yap, S.; Chuen Onn, C.; Wah Yuen, C.; Adebayo Ibrahim, H. Utilisation of recycled concrete aggregates for sustainable highway pavement applications; a review. Constr. Build. Mater. 2020, 235, 117444. [CrossRef]

2. Brundtland, G.H. Our common future-Call for action. Environ. Conserv. 1987, 14, 291-294. [CrossRef]

3. Huang, Y.; Bird, R.N.; Heidrich, O. A review of the use of recycled solid waste materials in asphalt pavements. Resour. Conserv. Recycl. 2007, 52, 58-73. [CrossRef]

4. Qasrawi, H.; Asi, I. Effect of bitumen grade on hot asphalt mixes properties prepared using recycled coarse concrete aggregate. Constr. Build. Mater. 2016, 121, 18-24. [CrossRef]

5. Krausmann, F.; Gingrich, S.; Eisenmenger, N.; Erb, K.H.; Haberl, H.; Fischer-Kowalski, M. Growth in global materials use, GDP and population during the 20th century. Ecol. Econ. 2009, 68, 2696-2705. [CrossRef]

6. Villoria-Sáez, P.; Osmani, M. A diagnosis of construction and demolition waste generation and recovery practice in the European Union. J. Clean. Prod. 2019, 241, 118400. [CrossRef]

7. European Commision Eurostat. Eurostat Statistics for Waste Flow Generation. 2018. Available online: https://ec.europa.eu/eurostat/web/waste/data/database (accessed on 20 October 2020).

8. Akhtar, A.; Sarmah, A.K. Construction and demolition waste generation and properties of recycled aggregate concrete: A global perspective. J. Clean. Prod. 2018, 186, 262-281. [CrossRef]

9. Iacoboaea, C.; Aldea, M.; Petrescu, F. Construction and Demolition Waste-A Challenge for the European Union? Theor. Empir. Res. Urban Manag. 2019, 14, 30-52.

10. Chen, W.; Jin, R.; Xu, Y.; Wanatowski, D.; Li, B.; Yan, L.; Pan, Z. Adopting recycled aggregates as sustainable construction materials: A review of the scientific literature. Constr. Build. Mater. 2019, 218, 483-496. [CrossRef]

11. European Commision Eurostat. Recovery rate of Construction and Demolition Waste. 2018. Available online: https://ec.europa.eu/eurostat/databrowser/view/cei_wm040/default/table?lang=en (accessed on 22 February 2020).

12. European Commision Eurostat. Treatment of Waste by Waste Category, Hazardousness and Waste Management Operations. 2018. Available online: https://appsso.eurostat.ec.europa.eu/nui/ submitViewTableAction.do (accessed on 30 October 2020).

13. Ghisellini, P.; Cialani, C.; Ulgiati, S. A review on circular economy: The expected transition to a balanced interplay of environmental and economic systems. J. Clean. Prod. 2016, 114, 11-32. [CrossRef]

14. Reid, J.M.; Chandler, J.W.E.; Schiavi, I.; Hewitt, A.P.; Griffiths, R.; Bendall, E. Sustainable Choice of Materials for Highway Works A Guide for Local Authority Highway Engineers, PPR233 ed.; Transport Research Laboratory: Berkshire, UK, 2008; ISBN 0968-4093.

15. Dhir, R.; Brito, J.; Silva, R.V.; QunLye, C. Use of Recycled Aggregates in Geotechnical Applications. In Sustainable Construction Materials Recycled Aggregates; Woodhead Publishing: Duxford, UK, 2019; pp. 419-450. ISBN 9780081009857.

16. Cardoso, R.; Silva, R.V.; de Brito, J.; Dhir, R. Use of recycled aggregates from construction and demolition waste in geotechnical applications: A literature review. Waste Manag. 2016, 49, 131-145. [CrossRef] [PubMed]

17. Barbudo, A.; Agrela, F.; Ayuso, J.; Jiménez, J.R.; Poon, C.S. Statistical analysis of recycled aggregates derived from different sources for sub-base applications. Constr. Build. Mater. 2012, 28, 129-138. [CrossRef]

18. Cameron, D.A.; Azam, A.H.; Rahman, M.M. Recycled Clay Masonry and Recycled Concrete Aggregate Blends in Pavement. In Proceedings of the GeoCongress 2012 in Oakland California March 25-29, 2012; American Society of Civil Engineers: Reston, VA, USA, 2012; pp. 1532-1541.

19. Arulrajah, A.; Piratheepan, J.; Aatheesan, T.; Bo, M.W.; Asce, M. Geotechnical Properties of Recycled Crushed Brick in Pavement Applications. J. Mater. Civ. Eng. 2011, 23, 1444-1452. [CrossRef]

20. Diagne, M.; Tinjum, J.M.; Nokkaew, K. The effects of recycled clay brick content on the engineering properties, weathering durability, and resilient modulus of recycled concrete aggregate. Transp. Geotech. 2015, 3, 15-23. [CrossRef]

21. Silva, R.V.; de Brito, J.; Dhir, R.K. Use of recycled aggregates arising from construction and demolition waste in new construction applications. J. Clean. Prod. 2019, 236, 117629. [CrossRef]

22. Santos, J.; Bressi, S.; Cerezo, V.; Lo, D. SUP \& R DSS: A sustainability-based decision support system for road pavements. J. Clean. Prod. 2019, 206, 524-540. [CrossRef] 
23. Silva, R.V.; De Brito, J.; Dhir, R.K. Properties and composition of recycled aggregates from construction and demolition waste suitable for concrete production. Constr. Build. Mater. 2014, 65, 201-217. [CrossRef]

24. Vegas, I.; Ibañez, J.A.; Lisbona, A.; Sáez De Cortazar, A.; Frías, M. Pre-normative research on the use of mixed recycled aggregates in unbound road sections. Constr. Build. Mater. 2011, 25, 2674-2682. [CrossRef]

25. Gómez-Meijide, B.; Pérez, I.; Pasandín, A.R. Recycled construction and demolition waste in Cold Asphalt Mixtures: Evolutionary properties. J. Clean. Prod. 2016, 112, 588-598. [CrossRef]

26. De-Juan, M.S.; Gutiérrez, P.A. Study on the influence of attached mortar content on the properties of recycled concrete aggregate. Constr. Build. Mater. 2009, 23, 872-877. [CrossRef]

27. Rami M Alfaqawi Using recycles aggregate in hot asphalt mixtures in Gaza strip, The University of Nottingham Department. 2012. Available online: https://www.researchgate.net/profile/Rami_ Alfaqawi/publication/323848039_Using_recycled_aggregate_in_hot_asphalt_mixtures_in_Gaza_Strip/ links/5b32279f4585150d23d4c4c8/Using-recycled-aggregate-in-hot-asphalt-mixtures-in-Gaza-Strip.pdf (accessed on 3 November 2020).

28. Arisha, A.; Gabr, A.; El-Badawy, S.; Shwally, S. Using Blends of Construction \& Demolition Waste Materials and Recycled Clay Masonry Brick in Pavement. Procedia Eng. 2016, 143, 1317-1324. [CrossRef]

29. Brasileiro, L.L.; Pereira, F.M.D.S.; de Abreu Vieira, P.; de Matos „, J.M.E. Concrete production of hot asphalt using recycled aggregates CDW. Mater. Sci. Forum 2017, 881 MSF, 346-350. [CrossRef]

30. Herrador, R.; Pérez, P.; Garach, L.; Ordóñez, J. Use of Recycled Construction and Demolition Waste Aggregate for Road Course Surfacing. J. Transp. Eng. 2011, 138, 182-190. [CrossRef]

31. Cerni, G.; Colagrande, S. Resilient Modulus of Recycled Aggregates Obtained by Means of Dynamic Tests in a Triaxial Apparatus. Procedia Soc. Behav. Sci. 2012, 53, 475-484. [CrossRef]

32. Jiménez, J.R.; Agrela, F.; Ayuso, J.; López, M. A comparative study of recycled aggregates from concrete and mixed debris as material for unbound road sub-base. Mater. Constr. 2011. [CrossRef]

33. Gómez-Meijide, B.; Pérez, I. Effects of the use of construction and demolition waste aggregates in cold asphalt mixtures. Constr. Build. Mater. 2014, 51, 267-277. [CrossRef]

34. Leite, F.D.C.; Motta, R.D.S.; Vasconcelos, K.L.; Bernucci, L. Laboratory evaluation of recycled construction and demolition waste for pavements. Constr. Build. Mater. 2011, 25, 2972-2979. [CrossRef]

35. Del Rey, I.; Ayuso, J.; Galvín, A.; Jiménez, J.; Barbudo, A. Feasibility of Using Unbound Mixed Recycled Aggregates from CDW over Expansive Clay Subgrade in Unpaved Rural Roads. Materials 2016, 9, 931. [CrossRef]

36. Gautam, P.K.; Kalla, P.; Jethoo, A.S.; Agrawal, R.; Singh, H. Sustainable use of waste in flexible pavement: A review. Constr. Build. Mater. 2018, 180, 239-253. [CrossRef]

37. Thom, N. Principles of Pavement Engineering; Thomas Telford Publishing Ltd.: London, UK, 2008; ISBN 9780727734808.

38. Jiménez, J.R.J.R.; Ayuso, J.; Agrela, F.; López, M.; Galvín, A.P.A.P. Utilisation of unbound recycled aggregates from selected CDW in unpaved rural roads. Resour. Conserv. Recycl. 2012, 58, 88-97. [CrossRef]

39. Morafa, S.H.; Saesaei, A.H.; Mahdizadeh Gohari, O.; Heidari Afshar, M.J. An experimental investigation on applying the recycled aggregates obtained from oil contaminated concrete exposed to seawater as road unbound pavement materials. Constr. Build. Mater. 2017, 157, 292-299. [CrossRef]

40. Nataatmadja, A.; Tan, Y.L. Resilient Response of Recycled Concrete Road Aggregates. J. Transp. Eng. 2001, 127, 450-453. [CrossRef]

41. Park, T. Application of construction and building debris as base and subbase materials in rigid pavement. J. Transp. Eng. 2003, 129, 558-563. [CrossRef]

42. Poon, C.S.; Chan, D. Feasible use of recycled concrete aggregates and crushed clay brick as unbound road sub-base. Constr. Build. Mater. 2006, 20, 578-585. [CrossRef]

43. Gabr, A.R.; Cameron, D.A. Properties of Recycled Concrete Aggregate for Unbound Pavement Construction. J. Mater. Civ. Eng. 2012, 24, 754-764. [CrossRef]

44. Tahmoorian, F.; Samali, B.; Tam, V.; Yeaman, J. Evaluation of Mechanical Properties of Recycled Material for Utilization in Asphalt Mixtures. Appl. Sci. 2017, 7, 763. [CrossRef]

45. Agrela, F.; Barbudo, A.; Ramírez, A.; Ayuso, J.; Dolores, M. Construction of road sections using mixed recycled aggregates treated with cement in Malaga, Spain. Resour. Conserv. Recycl. 2012, 58, 98-106. [CrossRef]

46. Tahmoorian, F.; Samali, B. Laboratory investigations on the utilization of RCA in asphalt mixtures. Int. J. Pavement Res. Technol. 2018, 11, 627-638. [CrossRef] 
47. Paige-Green, P. Strength and Behavior of Materials for Low-Volume Roads as Affected by Moisture and Density. Transp. Res. Rec. J. Transp. Res. Board 2003, 1819, 104-109. [CrossRef]

48. Rahman, M.A.; Imteaz, M.A.; Arulrajah, A.; Piratheepan, J.; Disfani, M.M. Recycled construction and demolition materials in permeable pavement systems: Geotechnical and hydraulic characteristics. J. Clean. Prod. 2015, 90, 183-194. [CrossRef]

49. Azam, A.M.; Cameron, D.A. Geotechnical properties of blends of recycled clay masonry and recycled concrete aggregates in unbound pavement construction. J. Mater. Civ. Eng. 2013, 25, 788-798. [CrossRef]

50. Garg, N.; Larkin, A.; Brar, H. A comparative subgrade evaluation using CBR, vane shear, light weight deflectometer, and resilient modulus tests. In Bearing Capacity of Roads, Railways and Airfields: Proceedings of the 8th International Conference on the Bearing Capacity of Roads, Railways and Airfields, Champaign, IL, USA, 29 June-2 July 2009; Taylor \& Francis Group, LLC.: Boca Raton, FL, USA, 2009; pp. 57-64.

51. O'Mahony, M.M.; Milligan, G.W.E. Use of recycled materials in subbaselayers. Transp. Res. Rec. 1991, 1310, 73-80.

52. Jiménez, J.R.; Agrela, F.; Ayuso, J.; López, M. Estudio comparativo de los áridos reciclados de hormigón y mixtos como material para sub-bases de carreteras. Mater. Constr. 2011, 61, 289-302. [CrossRef]

53. Lancieri, F.; Marradi, A.; Mannucci, S. C\&D waste for road construction: Long time performance of roads constructed using recycled aggregate for unbound pavement layers. WIT Trans. Ecol. Environ. 2006, 92, 559-569. [CrossRef]

54. Ayan, V.; Azadani, S.M.N.N.; Omer, J.R.; Limbachiya, M.C. Assessment of Toughness Performance of Recycled Aggregates for Use in Highway Pavement. In Proceedings of the Airfield and Highway Pavement 2013; American Society of Civil Engineers: Reston, VA, USA, 2013; pp. 1278-1290.

55. Moossazadeh, J.; Witczak, M. Prediction of Subgrade Moduli for Soil that Exhibits Nonlinear Behavior. Transp. Res. Rec. 1981, 810, 9-17.

56. Dhir, R.K.; de Brito, J.; Silva, R.V.; Lye, C.Q. Environmental Impact, Case Studies and Standards and Specifications. In Sustainable Construction Materials; Woodhead Publishing: Duxford, UK, 2019; pp. 495-583. ISBN 9780081009857.

57. Gourley, P. The Centre to Provide Waste Management Services and Recycled Aggregates to the Construction and Groundworks Sectors. Available online: https://www.insider.co.uk/news/brewster-bros-recycling-plantlivingston-13108730 (accessed on 11 February 2020).

58. Leek, C.; Siripun, K.; Nikraz, H.; Jitsangiam, P. An Investigation into the Performance of Recycled Concrete Aggregate as a Base Course Material in Road Pavements. In Proceedings of the International Conference on Advances in Geotechnical Engineering (ICAGE 2011), Perth, Australia, 7-9 November 2011; pp. 7-9, 343-349.

Publisher's Note: MDPI stays neutral with regard to jurisdictional claims in published maps and institutional affiliations.

(C) 2020 by the authors. Licensee MDPI, Basel, Switzerland. This article is an open access article distributed under the terms and conditions of the Creative Commons Attribution (CC BY) license (http://creativecommons.org/licenses/by/4.0/). 